\title{
Measurement of embodied carbon and energy of HVAC facilities in healthcare centers
}

\author{
Justo García-Sanz-Calcedo a, *, Nuno de Sousa Neves b , João Paulo Almeida Fernandes b \\ ${ }^{a}$ Department of Graphical Expression. Engineering Projects Section. University of Extremadura, 06006, Badajoz, Spain \\ ${ }^{\mathrm{b}}$ Department of Paisagem, Ambiente e Ordenamento. University of Evora, 7000, Evora, Portugal
}

\section{A R T I C L E I N F O}

\section{Article history:}

Received 7 March 2020

Received in revised form

5 November 2020

Accepted 13 November 2020

Available online 18 November 2020

Handling editor: Prof. Jiri Jaromir Klemeš

\section{Keywords:}

HVAC facilities

Healthcare engineering

Building projects

Embodied energy

Embodied carbon

Life cycle

\begin{abstract}
A B S T R A C T
The design of a sustainable building should include a reduction of its energy consumption, by considering the embodied energy and $\mathrm{CO}_{2}$ emissions generated during material manufacturing, transport and construction processes. A Heating, Ventilation and Air Conditioning (HVAC) facility in buildings consumes large amounts of energy. The aim of this work is to quantify the embodied carbon and energy of HVAC systems installed in healthcare centers. For this purpose, 6 healthcare centers in the region of Extremadura (Spain) -projected between 2006 and 2009 and built between 2007 and 2010- were analyzed. The results show that the embodied carbon -considering HVAC installations lifetime estimated at 15 years-is equivalent to the $\mathrm{CO}_{2}$ emitted for 2.3 years in the operation phase, and that the embodied energy is approximately 2.65 times the amount used in one year during that phase. Particularly, the average embodied carbon and energy is $48.95 \mathrm{~kg}$ of $\mathrm{CO}_{2}$ and $587.32 \mathrm{MJ}$ per $\mathrm{m}^{2}$, respectively, discarding the environmental impact of refrigerant gases. Additionally, different reference indicators are proposed to calculate both parameters according to different structural variables of a given healthcare center, including number of users, number of staff, HVAC installation costs, electrical power and average annual energy consumption.
\end{abstract}

(C) 2020 Elsevier Ltd. All rights reserved.

\section{Introduction}

Embodied energy, also known as grey energy, is the total energy required for the construction of a building, including the energy used for materials manufacturing, transport and machinery during the working process (Monahan and Powell, 2011). A low energy building does not qualify as sustainable, since we would only be considering its use phase and not its entire life cycle (Gao et al., 2018). High performance buildings, such as hospitals and healthcare centers, consume a significant proportion of the world's resources (García-Sanz-Calcedo et al., 2019). According to Eurostat, the building sector alone is responsible for $40 \%$ of $\mathrm{CO}_{2}$ emissions, $60 \%$ of raw material consumption, $50 \%$ of water consumption and $35 \%$ of waste generation (European Commission, 2019).

Building energy consumption and carbon dioxide emissions are expected to double, or even triple, by the middle of the 21st century (Lucon et al., 2014). However, efforts are currently focused on

\footnotetext{
* Corresponding author.

E-mail addresses: jgsanz@unex.es (J. García-Sanz-Calcedo),nneves@uevora.pt (N. de Sousa Neves), jpaf@uevora.pt (J.P. Almeida Fernandes).
}

reducing the operational energy usage in buildings, while the carbon and energy incorporated during their construction is expected to increase in the future (Yeo et al., 2016). This is explained by the fact that reduction of operational energy often implies an increase in emissions from the incorporation of high embodied energy in materials during manufacturing processes (Ramesh et al., 2010). Moreover, Ibn-Mohammed et al. (2013) demonstrate that the increasing proportion of embodied emissions of buildings is a consequence of the efforts to reduce operational emissions. Additionally, in a sample of 238 buildings, Röck et al., 2020 showed a clear reduction of greenhouse gas emissions due to improved energy efficiency, although there is an increase in embodied emissions from the manufacturing of building materials.

Healthcare centers are buildings designed to perform Primary Healthcare functions, including illness prevention, health promotion and treatment of patients. These buildings differ from hospitals since they are not designed to assist either hospitalization of patients or surgery interventions (Garcia-Sanz-Calcedo et al., 2018). On the other hand, this type of building typology is not well known. Due to the intensive use of their installations, they generate a high energy consumption and $\mathrm{CO}_{2}$ emissions (Salman Ali Salman, 2017). 
Heating, Ventilation and Air Conditioning (HVAC) installations affect air treatment in terms of cooling, heating, dehumidification, quality, and movement (Cohen et al., 2017). An HVAC system provides adequate airflow, heating and cooling to each area, maintaining the required values of temperature, humidity and air quality (Carretero-Ayuso et al., 2020).

Al-Waked et al. (2017) demonstrated the importance of using low energy HVAC systems and insulation strategies to contribute to high energy rating buildings. Gaglia et al. (2007) evaluated different energy conservation scenarios and their impact on the reduction of $\mathrm{CO}_{2}$ emissions of non-residential building stock. They observed that the most effective energy conservation measures including: installation of thermal insulation in exposed external walls, primarily in hotels and hospitals; provision of energy efficient lamps; solar collectors facility for domestic hot water production, primarily in hotels and healthcare centers; installation of building management systems in office, commercial and hotel buildings; replacement of old inefficient boilers; and regular maintenance of central heating boilers.

Dixit et al. (2010) identified parameters as a database to evaluate the energy incorporated in a building. Shahrestani et al. (2018) observed in the U.K. that different climate scenarios, electricity decarbonisation plans and building location are influential parameters to select HVAC systems. Dixit et al. (2012) concluded that it would be sensible to develop guidelines that could pave the way for an embodied energy protocol.

Using inventory of carbon and energy database, Hammond and Jones (2008) conducted 14 case studies of newly constructed housing, and notes that there was similar embodied energy and carbon between houses and apartments. An increasing difference was observed when external works were taken into account (energy inputs for roads, connecting pathways, among others). Rosselló Batle (2019) obtained quantified values of embodied energy and carbon in a building $1775.75 \mathrm{kWh} / \mathrm{m}^{2}$ and $695.30 \mathrm{~kg} \mathrm{CO} /$ $\mathrm{m}^{2}$ respectively. García-Sanz-Calcedo et al. (2020) calculated the emissions associated with the construction of healthcare centers in Spain, determining that the average amount of embodied, $\mathrm{CO}_{2} \mathrm{e}$ per built surface area was of $1122.30 \mathrm{~kg} / \mathrm{m}^{2}$ and $1.24 \mathrm{~kg}$ per euro invested in the building construction. However, neither the embodied energy nor the energy consumption of the building was taken into account during the operation phase.

Dokka et al. (2013) analyzed a typical medium-size office in a four-story heated floor building in Norway, and found that the total in-built emissions from the HVAC installation was of $24 \mathrm{~kg} \mathrm{CO} 2 \mathrm{eq} /$ $\mathrm{m}^{2}$ by using SimaPro software. Ylmén et al. (2019) determined that, in an office building in Sweden, the total carbon emissions from HVAC systems was of $38 \mathrm{~kg} \mathrm{CO} \mathrm{CO}_{2} \mathrm{e} \mathrm{m}^{2}$ in the production phase, and $100 \mathrm{~kg} \mathrm{CO} 2 \mathrm{e} / \mathrm{m}^{2}$ in the operation phase. Kiamili et al. (2020) evaluated the life cycle of HVAC systems in a newly constructed office building modeled at Building Information Modeling (BIM) in Switzerland, and found that the built-in impact of HVAC systems was of $183 \mathrm{~kg} \mathrm{CO} 2 \mathrm{e} / \mathrm{m}^{2}$. Shuo (2011) analyzed the environmental impact of three different HVAC installations, including a variable air volume (VAV) system, a chilled beam system and an underfloor air distribution (UAD) in an office building study. The total embodied carbon emission was of $21.01 \mathrm{~kg} \mathrm{CO} / \mathrm{m}^{2}, 42.70 \mathrm{~kg} \mathrm{CO} / 2 \mathrm{~m}^{2}$ and $9.2 \mathrm{~kg} \mathrm{CO} / \mathrm{m}^{2}$, respectively. However, none of the above authors took into account variables related to number of users, investment costs or energy demand, among others.

Quantifying the energy and emissions incorporated into the construction process of a building is a complex matter since not all the emissions incorporated into the manufacturing process of materials are available in databases (Zhang and Wang, 2017), so this information has to be directly requested from the manufacturer. Consequently, this procedure consumes more resources than when the operation energy is quantified (Dixit, 2017a,b). In term of design, construction and operation, healthcare buildings differ substantially from office buildings. Although there are previous studies focused on office buildings, most Life Cycle Analyses address edifications designed and constructed as low energy buildings (Cabeza et al., 2014).

As a novelty in this field, this research study aims to quantify the embodied carbon and energy of HVAC systems in standard healthcare buildings run under normal operating and climatic conditions. Additionally, it seeks to develop benchmarks indicator in the design and developments of technical projects. This will facilitate the decision-making process during the design phase by carefully choosing environmentally friendly HVAC equipment and materials.

\section{Methodology}

\subsection{Characterization of the sample}

A healthcare center represents a continuous operation building. In the Autonomous Community of Extremadura (Spain), 6 healthcare centers belonging to the Regional Healthcare Service were analyzed. The buildings were under construction project between 2006 and 2009 and were built between 2007 and 2010. The healthcare centers were similar in terms of construction materials and procedure/design, location and type of building. They all had similar HVAC facilities, built surface area $\left(1325-3200 \mathrm{~m}^{2}\right)$, number of users $(4700-18,000)$ and thermo-hygrometric conditions in their location. These buildings followed the same maintenance strategy, although possible thermal bridges were not taken into account. The characteristics and numerical data of these healthcare centers are shown in Table 1.

The main differences among the buildings are location, size and number of users. The last one includes patients treated at the facility and other visitors for medical prescriptions, sick leaves, diagnose tests and check-ups, among others reasons. The staff members are full-time workers in the building.

All the technical projects for the above healthcare centers fulfilled the same legal requirements. Specifically, the Spanish Technical Building Code (CTE, 2006) and the Regulations on Thermal Installation in Buildings (RITE, 1998) were obeyed. This building presented similar thermal demand as well and 15 years of useful average life were estimated for their HVAC installations (Fuller and Petersen, 1996).

All the buildings were constructed with a concrete structure and unidirectional slabs and braced footing. There was an analogy between the composition of the building envelope's layers and other administrative buildings, although the material quality was higher than the average, with flat roofs to accommodate machinery and installations, external carpentry with thermal bridge breaks, facades with low thermal transmittance, low emissivity glass, and high performance HVAC installations. Specifically, all the HVAC system in the healthcare centers consisted of air-cooled heat pumps with axial flow fans, water distribution, rooftop units, heat

Table 1

Functional characteristics of the healthcare centers.

\begin{tabular}{llllll}
\hline Center & Built surface area $\left(\mathrm{m}^{2}\right)$ & Users & Staff & Construction year & Stories \\
\hline 1 & 1515 & 13359 & 22 & 2009 & 1 \\
2 & 1328 & 4700 & 16 & 2007 & 2 \\
3 & 2824 & 17844 & 40 & 2009 & 2 \\
4 & 3192 & 14951 & 34 & 2008 & 2 \\
5 & 2367 & 16500 & 22 & 2009 & 1 \\
6 & 1877 & 6984 & 19 & 2008 & 1 \\
\hline
\end{tabular}


recovery and free-cooling systems, with inverter technology. The refrigerant gas used in all air-cooled heat pumps was R-407C. However, the environmental impact of the refrigerant gas was not included in the calculations in order to be able to apply the results to future buildings, since current equipment uses different environmentally friendly refrigerant gases (Bobbo et al., 2019).

\subsection{Calculation process}

The following functional variables were analyzed: built surface area $\left(\mathrm{m}^{2}\right)$, number of users (no.), number of staff (no.), HVAC installation costs $(€)$, electrical power $(\mathrm{kW})$ and average annual energy consumption (kWh). In addition, an on-site visit was performed to each healthcare center in order to verify the accuracy of the building project execution. The inspection was carried out by a qualified senior engineer during the research process, who verified through a check list that all the building installations coincided with those reflected in the construction project. The analysis of building materials included greenhouse gas emissions and embodied energy. It was associated with the extraction, processing and production of building materials. With respect to transport, the study included labor and movement of materials. Final testing and commissioning of facilities were also part of the construction phase. All these processes taken into consideration in the calculations of the carbon footprint and embodied energy, considering a cradle-to-gate scope (Pomponi et al., 2018). The methodology flowchart is shown in Fig. 1.

Embodied energy and $\mathrm{CO}_{2}$ emissions were obtained from the BEDEC database (ITEC, 2019). Detailed budgets for each building project were used to quantify each construction material. Emissions of $0.788 \mathrm{~kg}$ of $\mathrm{CO}_{2}$ per $\mathrm{m}^{3}$ of water and $0.38 \mathrm{~kg}$ of $\mathrm{CO}_{2}$ per $\mathrm{kWh}$ of electricity used were considered (Ecological Transition Ministry, 2019). The total embodied $\mathrm{CO}_{2}$ emissions of each HVAC healthcare facility were calculated by adding the embodied carbon of each material used in the project multiplied by the total amount of material and adding the emissions from the construction and transportation processes, according to equation (1).

$C=\sum_{i=1}^{n}\left(c_{i} \times k_{i}\right)+c_{f}+c_{t}+c_{c}$

where $C$ is the total amount of embodied carbon in the HVAC healthcare facility, expressed in $\mathrm{kg}, c_{i}$ is the embodied carbon emissions of each material, $k_{i}$ is the amount of material used, $c_{f}$ the emissions incorporated into the building during the construction process, $c_{t}$ is the emissions from transport of materials and mobility

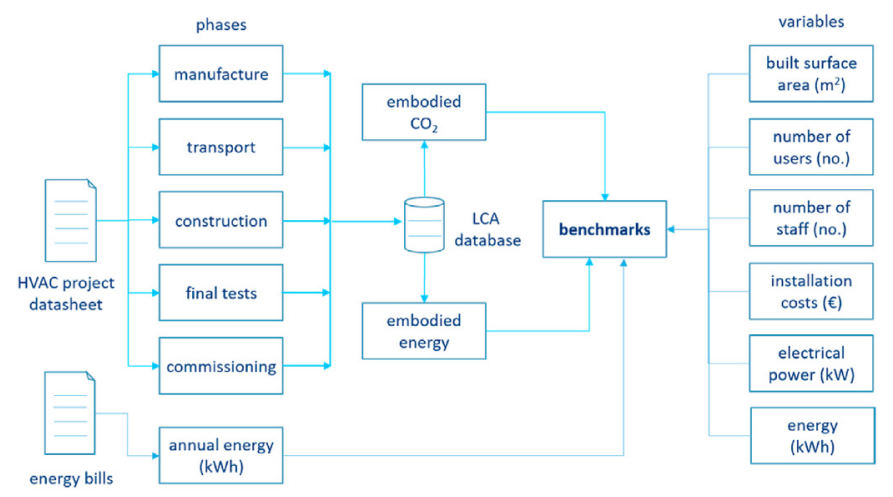

Fig. 1. Methodology flowchart. of workers, and $c_{c}$ indicates the emissions incorporated from the building construction.

The total embodied energy of each HVAC healthcare facility was calculated by adding the embodied energy of each material used in the project multiplied by the total amount of material and adding the energy from the construction and transportation processes, according to equation (2).

$E=\sum_{i=1}^{n}\left(e_{i} \times j_{i}\right)+e_{f}+e_{t}+e_{c}$

where $E$ is the total amount of embodied energy in the HVAC healthcare facility, expressed in $\mathrm{MJ}, e_{i}$ is the embodied energy of each material, $j_{i}$ is the amount of material used, $e_{f}$ is the energy incorporated into the building during the construction process, $e_{t}$ the energy needed for the transport of materials and mobility of workers, and $e_{c}$ correspond to the energy incorporated from the building construction.

To determine the number of workers who participated in the assembly and commissioning of the HVAC healthcare facility, the number of hours worked by each professional category was added from the construction project, considering a working an 8-h working day, 5 days a week.

In order to obtain those emissions related to worker mobility, an average occupancy of 4 people per vehicle was estimated. It was assumed that automotive diesel and 95-octane gasoline vehicles were used to transport materials and workers, respectively. Table 2 shows the amount of carbon dioxide emitted per kilometer travelled depending on the mode of transportation. These emissions from transport were estimated on the basis of fuel consumption only, assuming that the carbon fuel is fully oxidized into $\mathrm{CO}_{2}$ (European Environment Agency, 1997), according to equation (3).

$Q_{t}=44.011 \times \frac{Q}{\left(12.011+1.008 r_{H / C}\right)}$

being $Q t$ the emissions per $100 \mathrm{~km}$ expressed in $\mathrm{kg}$ of $\mathrm{CO}_{2}, Q$ the total fuel consumption of fuel per $100 \mathrm{~km}$, expressed in liters, and $r_{H / C}$ the relationship between the number of hydrogen and carbon atoms present in the combustion.

The average material transport distance was determined calculating the mean road distance from the point of manufacture to the healthcare center construction site, grouped by material types. Table 3 shows the average distance travelled to carry the HVAC materials to the site during the assembly process.

\subsection{Statistical analysis}

A statistical analysis of variance (ANOVA) was performed by comparing embodied carbon and energy of HVAC installations in healthcare centers, establishing the following hypotheses:

Table 2

$\mathrm{CO}_{2}$ emissions per kilometer, sorted by means of transport.

\begin{tabular}{ll}
\hline Vehicle & $\mathrm{kg} \mathrm{CO}_{2} / \mathrm{km}$ \\
\hline Motorcycles & 0.090 \\
Cars & 0.151 \\
Vans $<7.5$ tn & 0.317 \\
Trucks $7.5-16$ tn & 0.487 \\
Trucks $16-32$ tn & 0.659 \\
Trucks $>32$ tn & 0.788 \\
\hline
\end{tabular}


Table 3

Average distance travelled by HVAC materials.

\begin{tabular}{ll}
\hline Materials & $\begin{array}{l}\text { Distance }(\mathrm{km}) \\
(\mathrm{km})\end{array}$ \\
\hline Pipes & 300 \\
Machines and pumps & 600 \\
Ducts & 90 \\
Control systems & 400 \\
Waste & 80 \\
\hline
\end{tabular}

- Null hypothesis $\left(\mathrm{H}_{0}\right)$ : Those variables under analysis are not related to the embodied carbon and/or energy in the process of building a healthcare center.

- Alternative hypothesis $\left(\mathrm{H}_{1}\right)$ : The variables under study are related to the embodied carbon and/or energy in the process.

In order to detect differences statistically significant among the means of the studied factors and to assess the null hypothesis, the $p$-value was compared with the level of significance. In this sense, $5 \%$ (95\% confidence) was considered. When the $p$-value was lower than or equal to 0.05 , the null hypothesis was rejected, and consequently, not all population mean were equal. On the other hand, if the value of $p$ was over 0.05 , there was not enough evidence to discard the null hypothesis. Additionally, the statistical significance was obtained through $F$-Snedecor.

\section{Results and discussion}

The results obtained in this study are described in several sections.

\subsection{HVAC embodied carbon vs built surface area}

Fig. 2 shows the relationship between the embodied energy and carbon emissions per built surface area unit $\left(\mathrm{m}^{2}\right)$ of an HVAC facility and the size of a healthcare center. In particular, the embodied carbon per square meter is similar in all the buildings under study, while the embodied energy decreases inversely to the size of the building.

\subsection{HVAC embodied carbon vs annual $\mathrm{CO}_{2}$ emissions}

Fig. 3 shows the embodied carbon and annual $\mathrm{CO}_{2}$ operational emissions in HVAC installations in healthcare facilities. Assuming a lifetime of 15 years for a healthcare center HVAC installation, the

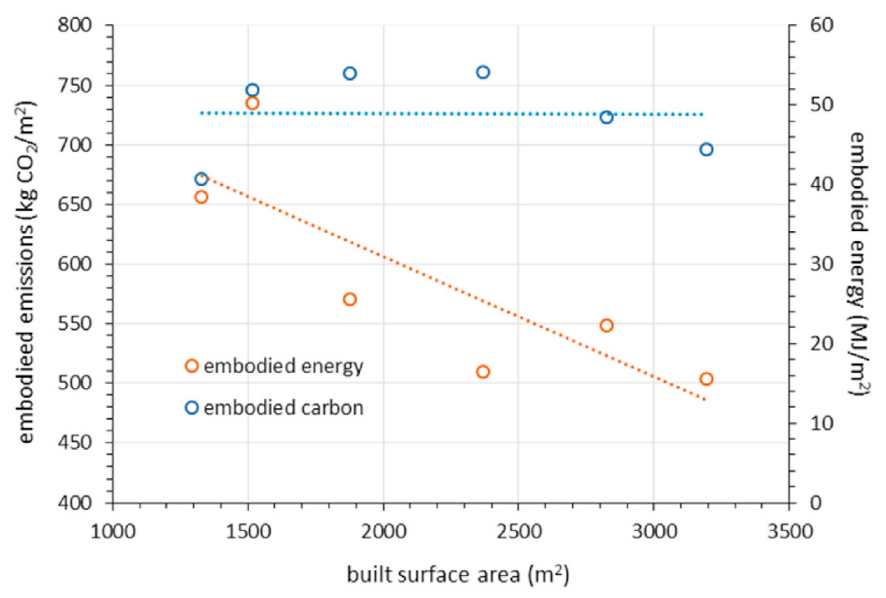

Fig. 2. Embodied carbon and energy per built surface area of an HVAC installation.

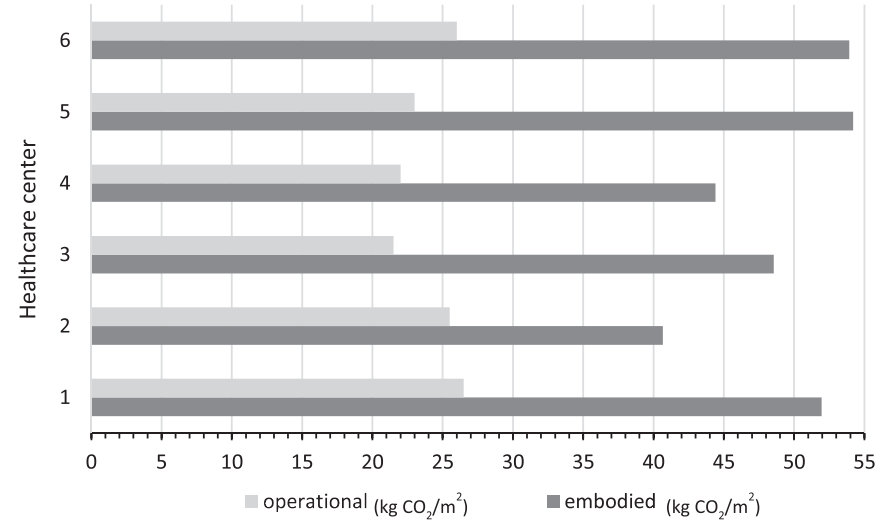

Fig. 3. Embodied carbon and annual $\mathrm{CO}_{2}$ operational emissions of healthcare center HVAC system.

average embodied carbon obtained was 2.30 times greater than the amount used in the operation phase of a healthcare center in one year.

\subsection{Embodied energy vs annual energy consumption}

Fig. 4 shows the embodied energy and the annual energy consumption of HVAC installations in a given healthcare center. For a period of 15 years, the embodied energy of the HVAC facility was estimated at 2.65 times the amount consumed by the healthcare center during the operation phase in one year.

\subsection{Embodied carbon benchmarks}

Table 4 shows the average embodied carbon, standard deviation and percentiles according to the reference indicators analyzed in the HVAC facility: unit of built surface area $\left(\mathrm{m}^{2}\right)$, financial investment in each facility $(€)$, number of users (no.), number of staff (no.), average annual energy consumption (kWh) and installed electrical power $(\mathrm{kW})$ in a healthcare center.

The most adequate reference indicators to quantify embodied carbon emissions are built surface area and annual energy consumption, since these present the lowest percentage of standard deviation. Reference indicators based on the number of users show a high variability. On the other hand, indicators based on installed electrical power are suitable. All the above indicators were validated for healthcare centers sized between 1000 and $3500 \mathrm{~m}^{2}$.

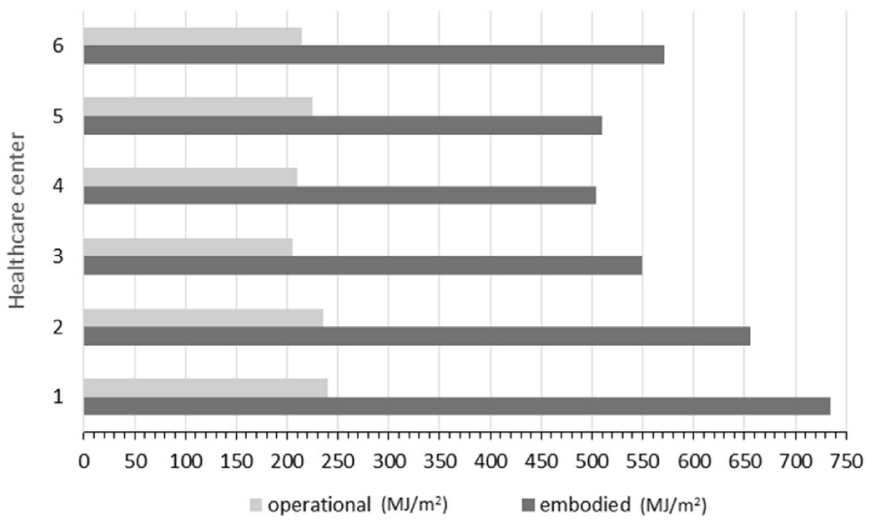

Fig. 4. Embodied energy and annual energy consumption of HVAC facilities in a healthcare center. 
Table 4

Embodied carbon indicators per functional unit of a healthcare center HVAC facility.

\begin{tabular}{lllllllll}
\hline ratio & average & $\begin{array}{l}\text { standard } \\
\text { deviation }\end{array}$ & \multicolumn{2}{l}{ percentiles } \\
\cline { 5 - 8 } \cline { 4 - 8 } & & & $10 \%$ & $25 \%$ & $50 \%$ & $75 \%$ & $90 \%$ \\
\hline $\mathrm{kg} \mathrm{CO}_{2} / \mathrm{m}^{2}$ & 48.95 & 5.01 & 42.54 & 45.45 & 50.25 & 53.44 & 54.06 \\
$\mathrm{~kg} \mathrm{CO}_{2} / €$ & 0.48 & 0.09 & 0.37 & 0.41 & 0.48 & 0.54 & 0.58 \\
$\mathrm{~kg} \mathrm{CO}_{2} / \mathrm{user}$ & 9.47 & 2.83 & 6.79 & 7.71 & 8.63 & 10.99 & 12.99 \\
$\mathrm{~kg} \mathrm{CO}_{2} / \mathrm{staff}$ & 4284 & 961 & 3401 & 3465 & 3873 & 5038 & 5579 \\
$\mathrm{~kg} \mathrm{CO}_{2} / \mathrm{kWh}$ & 0.49 & 0.06 & 0.41 & 0.46 & 0.51 & 0.52 & 0.55 \\
$\mathrm{~kg} \mathrm{CO} / \mathrm{kW}$ & 210 & 17 & 191 & 202 & 210 & 223 & 229 \\
\hline
\end{tabular}

By using suitable indicators, engineers and architects will have a reliable tool to design low environmental impact facilities, which will serve for future reference. On the one hand, healthcare managers will have the tools to control and benchmark those buildings they are responsible for. On the other, building maintenance managers will be able to set strategies to optimize their tasks by establishing control limits based on the indicators proposed in this study. Additionally, these indicators are useful to optimize initial ratios during renovation and refurbishment works.

Variable built surface area $\left(\mathrm{m}^{2}\right)$ is suitable to compare the environmental efficiency between different healthcare buildings. Variables number of users and number of staff monitor the use of healthcare spaces and the internal management of buildings, which encourages the construction of higher performance buildings. Variables electrical power (kW) and average annual energy consumption ( $\mathrm{kWh}$ ) are useful to control the energy used in a healthcare building during its operating phase. Finally, variable $H V A C$ installation costs $(€)$ allows to compare quality and costs of construction materials.

\subsection{Embodied energy benchmarks}

Table 5 includes the mean, standard deviation and percentiles of the indicators analyzed in the study, that is, embodied energy per unit of surface area $\left(\mathrm{m}^{2}\right)$, per investment $(€)$, per number of users (no.), per number of staff (no.), per average annual energy consumption $(\mathrm{kWh})$ and per installed electrical power $(\mathrm{kW})$.

Noticeably, embodied energy per unit of built surface area and per annual energy consumption are the most appropriate reference indicators to calculate the average embodied energy of an HVAC installation in a healthcare center, since these present the lowest standard deviation. These indicators are appropriate for healthcare centers between 1000 and $3500 \mathrm{~m}^{2}$. Indicators based on number of users and number of staff have a high variability and, therefore they are less suitable as reference.

The above results showed that HVAC facilities in healthcare centers sized between $1750 \mathrm{~m}^{2}$ and $2250 \mathrm{~m}^{2}$ produce less embodied energy and carbon per $\mathrm{m}^{2}(F=13.75 ; p=0.039)$. It was also noticed that healthcare centers with a construction investment over $1200 € / \mathrm{m}^{2}$ generates fewer emissions per $\mathrm{m}^{2}$ than others with

Table 5

Embodied energy indicators per functional unit of an HVAC facility in a healthcare center.

\begin{tabular}{lllllllll}
\hline ratio & average & $\begin{array}{l}\text { standard } \\
\text { deviation }\end{array}$ & \multicolumn{2}{l}{ percentiles } \\
\cline { 5 - 8 } & & & $10 \%$ & $25 \%$ & $50 \%$ & $75 \%$ & $90 \%$ \\
\hline $\mathrm{MJ} / \mathrm{m}^{2}$ & 587 & 83 & 506 & 519 & 560 & 635 & 695 \\
$\mathrm{MJ} / €$ & 5.87 & 1.90 & 4.49 & 5.05 & 5.37 & 5.58 & 7.77 \\
$\mathrm{MJ} / \mathrm{user}$ & 115 & 41 & 78 & 84 & 97 & 142 & 169 \\
$\mathrm{MJ} / \mathrm{staff}$ & 50390 & 6018 & 43027 & 48123 & 52523 & 54723 & 55620 \\
$\mathrm{MJ} / \mathrm{kWh}$ & 5.92 & 1.13 & 4.78 & 5.05 & 5.85 & 6.04 & 7.12 \\
$\mathrm{MJ} / \mathrm{kW}$ & 2530 & 384 & 2168 & 2219 & 2379 & 2793 & 3042 \\
\hline
\end{tabular}

an investment of less than $1000 € / \mathrm{m}^{2}(F=11.69 ; p=0.046)$. No significant differences between investment per built surface area and embodied carbon and energy per $\mathrm{m}^{2}(F=0.1596 ; p=0.763)$ were found.

Pearson's correlation coefficient between embodied energy and embodied carbon per built surface area and size of a healthcare center was of $0.782(\mathrm{sig}=0.000004)$ and $0.748(\mathrm{sig}=0.000002)$, respectively, which indicates that there is a significant correlation between these two variables. The value of Durbin-Watson statistics was of 1.218 and 1.324 , both close to 2 , implying there was no correlation between residues. Additionally, $85 \%$ of the points were within the interval $[-2,2]$. Therefore, the homoscedasticity of the intervening variables is assured. The validity of the proposed reference indicators was also checked. Fig. 5 plots the recommended reference indicators and variability according to the statistical analysis.

It has been shown that the embodied energy in a construction process is very high compared to that consumed during the operation phase, so it should not be ignored. $\mathrm{CO}_{2}$ emissions generated in the operation phase could be reduced by using renewable energy sources, or by purchasing green energy from the providers (Vares et al., 2019).

During the operation phase of a healthcare center, environmental impacts must be differentiated between operation and maintenance activities, and further disaggregated by installation: heating, cooling, ventilation, DHW, lighting, among others (Dixit, 2017a,b). It should be kept in mind that adequate energy use in the operational phase also reduces the environmental impact of the building (Madlool, 2018). Therefore, it is advisable to implement an energy management system through ISO 50001:2018. Furthermore, a correct energy management of the building should be carried out, including user awareness addressed to energy saving, and an adequate maintenance strategy (Lin et al., 2018).

On the other hand, the embodied energy and carbon from the construction phase is stable during the life of a facility (Tang et al., 2013). Therefore, it is very important to minimize the environmental impact throughout the building construction process ( $\mathrm{Oh}$ et al., 2017). To achieve that, is advisable to considerer the energy consumed in the operation phase, as well as the embodied and recurrent energies in order to select adequate equipment and design efficient HVAC systems. Additionally, it is recommendable to incorporate bioclimatic techniques in the design of the building (Camara et al., 2017), promote natural ventilation through freecooling, use insulating materials with low environmental impact and avoid thermal bridges in the building envelope.

Paradoxically, energy rate systems in buildings do not usually consider either embodied carbon or embodied energy. From a

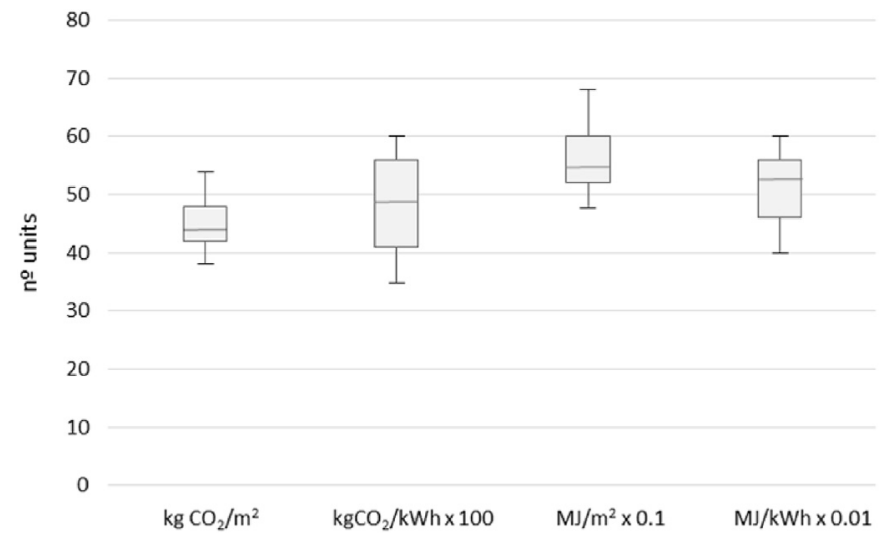

Fig. 5. Indicators of embodied carbon and energy in healthcare centers. 
medium-term perspective, operational energy will progressively decrease during the useful life of a healthcare center (Koezjakov et al., 2018) due to low-consumption equipment, advanced insulation materials and greater user awareness. Also, new devices will include components, such as printed circuit boards and transducers, designed with low impact materials (Ordoñez-Durán et al., 2020). Therefore, the relationship between embodied and operational energies will change proportionally.

It has been observed that healthcare centers generate more emissions in their construction process than other buildings in the tertiary sector for several reasons: they include sophisticated installations, their structure has greater spans, their enclosures are better thermally insulted and their indoor materials are prepared to withstand intensive use. Furthermore, in order to determine the embodied energy and carbon of the HVAC facilities in healthcare centers, built surface area $\left(\mathrm{m}^{2}\right)$ was the most appropriate functional variable. However, it is also interesting to use other functional variables, such as number of users, since the intensity of use of the building could be integrated into the analysis. It should be kept in mind that, with the same embodied energy in the construction, a healthcare building serving a larger number of users is more efficient environmentally (To et al., 2018). HVAC installation costs (€) is a variable that compares the quality of the equipment among different buildings, and it also controls the embodied emissions in buildings (Copiello and Bonifaci, 2017).

It was further noted that transport constituted $3 \%$ of the total $\mathrm{CO}_{2}$ emissions in the construction phase. The impact of transporting materials and workers could be reduced by using public transport and hybrid and/or electric vehicles. Another effective measure would be to organize purchasing and material collection policies in order to optimize transport and delivery with largercapacity trucks and fewer trips. In other words, there should be subcontract agreements including the share of trucks and reduction of trips, implying the gathering of materials on site.

The purpose of a circular economy is to beame an alternative system that, in turn, can be remanufactured with less energy consumption than the original (Den Hollander et al., 2017). By considering that concept during the construction of healthcare centers, the rates of greenhouse gas emissions could be substantially reduced (Pomponi and Moncaster, 2017). By all means, it is important to focus our efforts on evaluating the emissions generated in the process of building construction (Fenner et al., 2018), as a measure to move towards a circular economy (Fang et al., 2017).

The embodied energy of the materials should be contained during the construction phase by using more insulation materials, and glazing, and by introducing more advanced systems. During the design phase, it is important to select facilities based on the amount of embodied carbon and energy (Dias and Pooliyadda, 2004). On the other hand, equipment over-sizing and redundancy of installations significantly increase environmental emissions (Seifert et al., 2019). However, in healthcare centers, redundancy of critical facilities is necessary to ensure their resilience in case of emergencies or natural disasters (Zhong et al., 2017).

An adequate selection of HVAC refrigerant gas reduces the overall carbon footprint of a healthcare center (Devecioglu and Oruç, 2015). The use of natural refrigerants such as ammonia, carbon dioxide and hydrocarbons in vapour compression refrigeration systems, will reduce their environmental impact (Bhatkar et al., 2013). According to the standard (Mota-Babiloni et al., 2017), today new facilities must incorporate refrigerants with low Global Warming Potential (GWP). There are also improvements of $\mathrm{CO}_{2}$ systems by installing parallel compressors, ejectors as an expansion device and usage of evaporative condenser (Abas et al., 2018). The design of HVAC systems, including components with a long service life and adaptable for use in different configurations, has proved to be a reliable strategy that decreases embodied energy in the long term (Malmqvist et al., 2018). Furthermore, an adequate selection of the equipment is necessary considering that HVAC systems have a short lifespan compared to buildings. These modules are quite significant since they will be repeated 4 or 5 times throughout the building life.

Significantly, from a maintenance point of view, the regular change oh HVAC filters generates a substantially high environmental impact On the other hand, it is very important to consider that, at maintenance impact (Kiamili et al., 2020). It is also important to avoid refrigerant leaks at all times (Pomponi et al., 2018). Additionally, it is relevant to review the relationship between the rates of energy embodied in the materials used for the building and the amount of energy used in the construction (Kaspersen et al., 2016). Even when low energy consumption materials are used many of them could lead to an increase in embodied carbon and total energy in a facility (De Wolf et al., 2017). Increasing the use of a healthcare center during unexpected scenarios with higher services demand can increase the energy used in the operation phase and even decrease the lifetime of HVAC facilities if the intense use persists (Korolija et al., 2011). All healthcare centers analyzed in the sample were studied under normal operating conditions.

Comparing our findings with other studies, office buildings present higher amount of embodied carbon per square meter $\left(48.95 \mathrm{~kg} / \mathrm{m}^{2}\right)$ than those reported by other authors such as Dokka et al. $\left(24 \mathrm{~kg} / \mathrm{m}^{2}\right)$, Ylmén et al. $\left(38 \mathrm{~kg} / \mathrm{m}^{2}\right)$, and Shuo $\left(21.01 \mathrm{~kg} / \mathrm{m}^{2}\right)$, for office buildings. Our results are predictable since healthcare buildings are used more intensively and they also require better air quality (Fonseca et al., 2019). On the other hand, our results are similar to commercial buildings. Specifically, Rodriguez (2019) observed that the embodied carbon of HVAC systems was of 36, 46 and $54 \mathrm{~kg} / \mathrm{m}^{2}$ in large, medium and small buildings, respectively.

Although building construction methods are constantly evolving (Allen and Iano, 2019), the design criteria for HVAC facilities in healthcare centers have remained practically the same in the last few years due to their operational complexity. An appropriate installation requires specific indoor environment air quality, including: air ducts (Sanchez-Barroso and García-Sanz-Calcedo, 2019); pressure, humidity and temperature controls; and sectored zones (Moscato et al., 2017), among others. With respect to embodied energy and carbon, modern technologies intend to reduce GWP through low impact refrigerant gases (Bobbo et al., 2019) and electronic control systems (Felgueiras et al., 2016). In this study, the environmental impact of refrigerant gases used in the sample buildings was not taken into account, and the HVAC equipment included advanced control systems. On this basis, the results in this research study could be used as current and future reference for the design of HVAC installations.

There are several certifications and standards in order to classify buildings according to their energy demand (Crawford and Stephan, 2013). The Passivhaus standard, for example, aims to reduce energy demand during the use of buildings (RomanskaZapala et al., 2018). Additionally, those data available from the LEED documentation system on HVAC built-in carbon are limited (Rodriguez et al., 2019). Usually, these certifications do not include the embodied carbon and energy in the building material manufacturing (Jang et al., 2019). A full LCA based on ISO 14040-44 standards is advisable since it can provide additional information to evaluate the results of the building life cycle inventory (LCI) and help to better understand the overall environmental impact of the building (Dossche et al., 2017). BIM Technology can easily measure the embodied carbon and energy, avoiding both further costs and complex LCA software usage (Santos et al., 2019).

Designers are responsible for appropriate maintenance of buildings and their facilities throughout their useful life, including 
necessary reforms (Kalantari et al., 2017). Owners have to guarantee optimal conditions to preserve the initial design characteristics (Olanipekun et al., 2018). It is also recommended that the technical construction team to be involved in future evaluations of the building environmental performance (Passer et al., 2012). On the other hand, current inventories and methodologies for embodied energy need improvement due to their inaccuracy and lack of reliability (Finnegan et al., 2018). This problem derives from parameter variability and is related to various stages of embodied energy analysis (Morini et al., 2019).

\section{Practical implications of the present study}

The indicators here proposed serve as a reference to design sustainable HVAC systems, since they evaluate their environmental footprint from an integral perspective. They are helpful in terms of considering both embodied carbon and energy in the construction process of healthcare buildings, and of selecting the most appropriate materials (Cui et al., 2010). Additionally, they can be used as consumption and embodied energy references to encourage building energy saving (Dakwale et al., 2011).

The current legislation should limit the embodied carbon and energy levels during the construction phase of a given building. In this sense, the designer would have to choose minimal environmental impact materials. Therefore, our results serve to develop building energy rating systems that take into account embodied energy and carbon during construction, and our proposed indicators could be used as future reference (Simonen et al., 2017). That rating system will encourage material manufacturers to reduce embodied energy during production (Ortiz et al., 2009). In addition, Public Administrations should promote sustainable manufacturing policies that favor energy reduction, making it mandatory to include embodied emissions from manufacturing materials and equipment as part of technical data sheets.

Nowadays, the design of nearly zero-energy buildings is frequently encouraged. Thus, users and politicians expect environmentally friendly buildings (Causone et al., 2019). For this reason, it is necessary to work on raising society's awareness about the need to include embodied energy and emissions in the whole life of a building (Lotteau et al., 2017). In this sense, the results of this study could be helpful to benchmark and set improvement targets for buildings by healthcare managers, as well as to enhance the sustainability of facilities and their maintenance (Lord et al., 2016).

\section{Conclusions and future prospects}

In this study, we measured the carbon emissions and energy consumption of several HVAC facilities in their corresponding healthcare buildings. The results showed that the embodied carbon and embodied energy of these facilities was, respectively, 2.30 and 2.65 times greater than the amounts used during the operation phase of a healthcare center in one year.

By proposing different reference indicators about embodied energy and carbon, it is possible to calculate these parameters depending on several structural variables of the healthcare center (built surface area, number of users and staff, economic investment, electrical power and average annual energy consumption). It was observed that the average embodied carbon and energy of an HVAC healthcare facility was 48.95 ( $\mathrm{std}=5.01$ ) $\mathrm{kg}$ and 587.32 $(\mathrm{std}=82.84) \mathrm{MJ}$ per $\mathrm{m}^{2}$, respectively, discarding the environmental impact of refrigerant gases. It was also found that the average embodied carbon and energy consumed was $0.49(\mathrm{std}=0.06) \mathrm{kg}$ and 5.92 (std $=1.13$ ) MJ per kWh, respectively. Noticeably, the embodied energy of an HVAC installation per unit of built surface area decreased inversely to the size of the healthcare center.
For a building to qualify as energy efficient, it is necessary to use tools that analyze its life cycle, with special emphasis on the embodied energy of the materials. Proper labelling of those materials used in the construction process, as well as greenhouse gas emissions and embodied energy in the building, should therefore be required. In this manner, it will be possible to consider both embodied energy and carbon when carrying out energy qualification.

Conclusively, our results highlight the need to address the lifecycle-related embodied carbon and energy in healthcare buildings, with the possibility of extrapolating them to buildings with similar facilities and materials and to other countries with similar regulations and construction techniques.

Future works should focus on evaluating the embodied carbon and energy of other healthcare building facilities, such as electrical, water and medical gases installations, among others. It would also be necessary to introduce the calculation of recurrent embodied energy in healthcare building, that is, the energy used in the various processes for their maintenance and refurbishment (including materials and components) during their useful life. On the other hand, more case studies would be helpful to obtain a broader scenario about the embodied environmental impact of HVAC systems, thus collaborating in the defossilisation of the building sector. As a final observation, further research to document inventories of different types of HVAC systems is recommended in order to establish a useful database with complete and specific contents on embodied emission and energy in buildings.

\section{CRediT authorship contribution statement}

Justo García-Sanz-Calcedo: Conceptualization, Methodology, Software, Data curation, Writing - original draft, Validation, Investigation. Nuno de Sousa Neves: Visualization, Investigation. João Paulo Almeida Fernandes: Supervision, Software, Writing review \& editing, Investigation.

\section{Declaration of competing interest}

The authors declare that they have no known competing financial interests or personal relationships that could have appeared to influence the work reported in this paper.

\section{Acknowledgements}

The authors wish to express their acknowledgement to José Castillejo Program of the Spanish Ministry of Science, Innovation and Universities, to the VI Regional Research, Technological Development and Innovation Plan of the Government of Extremadura (GR-18029), and to the European Regional Development Fund for their financial support to Prof. García-Sanz-Calcedo during his work stay at the University of Evora (Portugal).

\section{References}

Abas, N., Kalair, A.R., Khan, N., Haider, A., Saleem, Z., Saleem, M.S., 2018. Natural and synthetic refrigerants, global warming: a review. Renew. Sustain. Energy Rev. 90, 557-569.

Al-Waked, R., Shakir Nasif, M., Groenhout, N., Partridge, L., 2017. Energy performance and $\mathrm{CO}_{2}$ emissions of HVAC systems in commercial buildings. Buildings 7 (4), 84.

Allen, E., Iano, J., 2019. Fundamentals of Building Construction: Materials and Methods. John Wiley \& Sons.

Bhatkar, V.W., Kriplani, V.M., Awari, G.K., 2013. Alternative refrigerants in vapour compression refrigeration cycle for sustainable environment: a review of recent research. Int. J. Environ. Sci. Technol. 10 (4), 871-880.

Bobbo, S., Fedele, L., Curcio, M., Bet, A., et al., 2019. Energetic and exergetic analysis of low global warming potential refrigerants as substitutes for R410A in ground source heat pumps. Energies 12 (18), 3538. 
Cabeza, L.F., Rincón, L., Vilariño, V., Pérez, G., Castell, A., 2014. Life cycle assessment (LCA) and life cycle energy analysis (LCEA) of buildings and the building sector: a review. Renew. Sustain. Energy Rev. 29, 394-416.

Camara, T., Kamsu-Foguema, B., Diourte, B., Maiga, A.I., Habbadi, A., 2017. Management and assessment of performance risks for bioclimatic buildings. J. Clean. Prod. 147, 654-667.

Carretero-Ayuso, M.J., Moreno-Cansado, A., García-Sanz-Calcedo, J., 2020. Evaluation of design faults in HVAC systems in housing: a study based on thermohygrometric variables. Science and Technology for the Built Environment 26, $177-184$.

Causone, F., Tatti, A., Pietrobon, M., Zanghirella, F., Pagliano, L., 2019. Yearly operational performance of a nZEB in the Mediterranean climate. Energy Build. 198, 243-260.

Cohen, R., Austin, B., Bannister, P., Bordass, B., Bunn, R., 2017. How the commitment to disclose in-use performance can transform energy outcomes for new buildings. Build. Serv. Eng. Technol. 38 (6), 711-727.

Copiello, S., Bonifaci, P., 2017. The relation between building costs and embodied energy: new insights. Int. J. Hous. Sci. Appl. 41 (2), 61-70.

Crawford, R.H., Stephan, A., 2013. The significance of embodied energy in certified passive houses. In: Proceedings of World Academy of Science, Engineering and Technology. World Academy of Science. Engineering and Technology, p. 453.

CTE. Spanish, 2006. Technical Building Code.

Cui, H.Z., Sham, F.C., Lo, T.Y., Lum, H.T., 2010. Appraisal of alternative building materials for reduction of $\mathrm{CO}_{2}$ emissions by case modelling. Int. J. Environ. Res. 5, 93-100.

Dakwale, V.A., Ralegaonkar, R.V., Mandavgane, S., 2011. Improving environmental performance of building through increased energy efficiency: a review. Sustainable Cities and Society 1 (4), 211-218.

Den Hollander, M.C., Bakker, C.A., Hultink, E.J., 2017. Product design in a circular economy: Development of a typology of key concepts and terms. J. Ind. Ecol. 21 (3), 517-525.

Devecioğlu, A.G., Oruç, V., 2015. Characteristics of some new generation refrigerants with low GWP. Energy Procedia 75, 1452-1457.

De Wolf, C., Pomponi, F., Moncaster, A., 2017. Measuring embodied carbon dioxide equivalent of buildings: a review and critique of current industry practice. Energy Build. 140, 68-80.

Dias, W.P.S., Pooliyadda, S.P., 2004. Quality based energy contents and carbon coefficients for building materials: a systems approach. Energy 29 (4), 561-580.

Dixit, M.K., 2017a. Life cycle embodied energy analysis of residential buildings: a review of literature to investigate embodied energy parameters. Renew. Sustain. Energy Rev. 79, 390-413.

Dixit, M.K., Fernández-Solís, J.L., Lavy, S., Culp, C.H., 2012. Need for an embodied energy measurement protocol for buildings: a review paper. Renew. Sustain. Energy Rev. 16 (6), 3730-3743.

Dixit, M.K., Fernández-Solís, J.L., Lavy, S., Culp, C.H., 2010. Identification of parameters for embodied energy measurement: a literature review. Energy Build. 42 (8), 1238-1247.

Dixit, M.K., 2017b. Embodied energy analysis of building materials: an improved IObased hybrid method using sectoral disaggregation. Energy 124, 46-58.

Dokka, T.H., Kristjansdottir, T.F., Time, B., Mellegård, S.E., Haase, M., Tønnesen, J., 2013. A Zero Emission Concept Analysis of an Office Building; ZEB Project Report. Norwegian University of Science and Technology, Trondheim.

Dossche, C., Boel, V., De Corte, W., 2017. Use of life cycle assessments in the construction sector: critical review. Procedia Engineering 171, 302-311.

Ecological Transition Ministry of Spain, 1998. Reglamento de Instalaciones Térmicas en los Edificios. RITE. R.D. 1751/1998.

European Commission, 2019. Consulted: 30 January 2020. https://ec.europa.eu/ energy/en/topics/energy-efficiency/energy-performance-of-buildings.

European Environment Agency, 1997. Computer programme to calculate emissions from road transport. Methodology and emission factors. https://www.eea. europa.eu/publications/TEC06/download. (Accessed 30 May 2020).

Fang, K., Dong, L., Ren, J., et al., 2017. Carbon footprints of urban transition: tracking circular economy promotions in Guiyang, China. Ecol. Model. 365, 30-44.

Fenner, A.E., Kibert, C.J., Woo, J., Morque, S., Lu, X., 2018. The carbon footprint of buildings: a review of methodologies and applications. Renew. Sustain. Energy Rev. 94, 1142-1152.

Felgueiras, C., Santos, R., Fonseca, L., Caetano, N.S., 2016. Buildings sustainability: the HVAC contribution. Journal of Clean Energy Technologies-JOCET 4 (5), $375-379$.

Finnegan, S., Jones, C., Sharples, S., 2018. The embodied $\mathrm{CO}_{2} \mathrm{e}$ of sustainable energy technologies used in buildings: a review article. Energy Build. 181, 50-61.

Fonseca, A., Abreu, I., Guerreiro, M.J., Abreu, C., Silva, R., Barros, N., 2019. Indoor air quality and sustainability management. Case study in three Portuguese healthcare units. Sustainability 11 (1), 101.

Fuller, S., Petersen, S., 1996. Life-cycle costing manual for the federal energy management Program. NIST Handbook 135, 1995 Edition.

Gaglia, A.G., Balaras, C.A., Mirasgedis, S., Georgopoulou, E., Sarafidis, Y., Lalas, D.P., 2007. Empirical assessment of the Hellenic non-residential building stock, energy consumption, emissions and potential energy savings. Energy Convers. Manag. 48 (4), 1160-1175.

Gao, J., Li, A., Xu, X., Gang, W., Yan, T., 2018. Ground heat exchangers: applications, technology integration and potentials for zero energy buildings. Renew. Energy 128, 337-349.

Garcia-Sanz-Calcedo, J., Al-Kassir, A., Yusaf, T., 2018. Economic and environmental impact of energy saving in healthcare buildings. Appl. Sci. 8 (3), 440.
García-Sanz-Calcedo, J., Gomez-Chaparro, M., Sanchez-Barroso, G., 2019. Electrical and thermal energy in private hospitals: consumption indicators focused on healthcare activity. Sustainable Cities and Society 47, 101482.

García-Sanz-Calcedo, J., Neves, N., Fernandes, J.P., 2020. Assessment of the globalwarming potential associated with the construction process of healthcare centres. J. Build. Phys. https://doi.org/10.1177/1744259120914333 (in press).

Hammond, G.P., Jones, Ci, 2008. Embodied energy and carbon in construction materials. Proceedings of the Institution of Civil Engineers-Energy 161 (2), 87-98.

Ibn-Mohammed, T., Greenough, R., Taylor, S., Ozawa-Meida, L., Acquaye, A., 2013. Operational vs. embodied emissions in buildings - a review of current trends. Energy Build. 66, 232-245.

Instituto de Tecnología de la Construcción (ITEC) Banco ITEC2019, 2019. Environmental Data. ITEC. Barcelona, Spain.

International Organization for Standardization ISO 50001:2018, 2018. Energy Management Systems (Geneva, Switzerland).

Jang, J., Lee, J., Son, E., Park, K., Kim, G., Lee, J.H., Leigh, S.B., 2019. Development of an improved model to predict building thermal energy consumption by utilizing feature selection. Energies 12 (21), 4187.

Kalantari, S., Shepley, M.M., Rybkowski, Z.K., Bryant, J., 2017. Collaboration between designers and facility managers. Facilities 35 (9/10), 557-572.

Kaspersen, B., Lohne, J., Bohne, R.A., 2016. Exploring the $\mathrm{CO}_{2}$-impact for building height: a study on technical building installations. Energy Procedia 96, 5-16.

Kiamili, C., Hollberg, A., Habert, G., 2020. Detailed assessment of embodied carbon of HVAC systems for a new office building based on BIM. Sustainability 12 (8), 3372, 2020.

Koezjakov, A., Urge-Vorsatz, D., Crijns-Graus, W., Van den Broek, M., 2018. The relationship between operational energy demand and embodied energy in Dutch residential buildings. Energy Build. 165, 233-245.

Korolija, I., Marjanovic-Halburd, L., Zhang, Y., Hanby, V.I., 2011. Influence of building parameters and HVAC systems coupling on building energy performance. Energy Build. 43 (6), 1247-1253.

Lin, M., Afshari, A., Azar, E., 2018. Un análisis basado en datos del uso de energía en edificios con énfasis en la operación y mantenimiento: un estudio de caso de los. EAU Journal of Cleaner Production 192, 169-178.

Lord, S.F., Noye, S., Ure, J., Tennant, M.G., Fisk, D.J., 2016. Comparative review of building commissioning regulation: a quality perspective. Build. Res. Inf. 44 (5-6), 630-643.

Lotteau, M., Loubet, P., Sonnemann, G., 2017. An analysis to understand how the shape of a concrete residential building influences its embodied energy and embodied carbon. Energy Build. 154, 1-11.

Lucon, O., Ürge-Vorsatz, D., Ahmed, A.Z., et al., 2014. Buildings Climate Change 2014: Mitigation of Climate Change. Contribution of Working Group III to the Fifth Assessment Report of the Intergovernmental Panel on Climate Change. Cambridge University Press, United Kingdom and New York, NY, USA.

Madlool, N.A., 2018. Building energy performance and the influence of the operational parameters in an educational hospital. Journal of University of Babylon for Engineering Sciences 26 (2), 69-77.

Malmqvist, T., Nehasilova, M., Moncaster, A., Birgisdottir, H., Rasmussen, F.N., Wiberg, A.H., Potting, J., 2018. Design and construction strategies for reducing embodied impacts from buildings - case study analysis. Energy Build. 166 (1), 35-47.

Monahan, J., Powell, J.C., 2011. An embodied carbon and energy analysis of modern methods of construction in housing: a case study using a life cycle assessment framework. Energy Build. 43 (1), 179-188.

Morini, A.A., Ribeiro, M.J., Hotza, D., 2019. Early-stage materials selection based on embodied energy and carbon footprint. Mater. Des. 178, 107861.

Moscato, U., Borghini, A., Teleman, A.A., 2017. HVAC Management in Health Facilities. Indoor Air Quality in Healthcare Facilities. Springer, Cham, pp. 95-106.

Mota-Babiloni, A., Navarro-Esbrí, J., Makhnatch, P., Molés, F., 2017. Refrigerant R32 as lower GWP working fluid in residential air conditioning systems in Europe and the USA. Renew. Sustain. Energy Rev. 80, 1031-1042.

Oh, B.K., Choi, S.W., Park, H.S., 2017. Influence of variations in $\mathrm{CO}_{2}$ emission data upon environmental impact of building construction. J. Clean. Prod. 140, $1194-1203$.

Olanipekun, A.O., Xia, B., Hon, C., Darko, A., 2018. Effect of motivation and owner commitment on the delivery performance of green building projects. J. Manag. Eng. 34 (1), 04017039.

Ordoñez-Durán, J.F., Chimenos, J.M., Segarra, M., de Antonio Boada, P.A., Espindola Ferreira, J.C., 2020. Analysis of embodied energy and product lifespan: the potential embodied power sustainability indicator. Clean Technol. Environ. Policy 1-14.

Ortiz, O., Castells, F., Sonnemann, G., 2009. Sustainability in the construction industry: a review of recent developments based on LCA. Construct. Build. Mater. 23 (1), 28-39.

Passer, A., Kreiner, H., Maydl, P., 2012. Assessment of the environmental performance of buildings: a critical evaluation of the influence of technical building equipment on residential buildings. Int. J. Life Cycle Assess. 17, 1116-1130.

Pomponi, F., Moncaster, A., 2017. Circular economy for the built environment: a research framework. J. Clean. Prod. 143, 710-718.

Pomponi, F., Moncaster, A., De Wolf, C., 2018. Furthering embodied carbon assessment in practice: results of an industry-academia collaborative research project. Energy Build. 167, 177-186.

Röck, M., Mendes Saade, M.R., Balouktsi, M., Nygaard Rasmussen, F., Birgisdottir, H., et al., 2020. Embodied GHG emissions of buildings - the hidden challenge for 
effective climate change mitigation. Appl. Energy 258, 114107.

Rodriguez, B., 2019. Embodied Carbon of Heating, Ventilation, Air Conditioning and Refrigerants (HVAC + R) Systems. Doctoral Thesis.

Rodriguez, B.X., Amany, L., Simonen, K., 2019. Embodied and operational carbon of typical heating, ventilation and air conditioning (HVAC) systems in office buildings in Washington state: a study of buildings registered under LEED v3 2009. In: IOP Conference Series: Earth and Environmental Science. IOP Publishing, 012057.

Rosselló Batle, B., 2019. Análisis de la energía consumida y las emisiones de $\mathrm{CO}_{2}$ durante el ciclo de vida de edificios del sector terciario y residencial situados en las Islas Baleares. Universitat de les Illes Balears. Spain. Doctoral Thesis.

Ramesh, T., Prakash, R., Shukla, K.K., 2010. Life cycle energy analysis of buildings: an overview. Energy Build. 42 (10), 1592-1600.

Romanska-Zapala, A., Bomberg, M., Yarbrough, D.W., 2018. Buildings with environmental quality management: Part 4: a path to the future NZEB. J. Build. Phys. 43 (1), 3-21.

Salman Ali Salman, S., 2017. Enhancing Environmental Sustainability of Healthcare Facilities: a System Dynamics Analysis Approach. Brunel University London, p. 2016. Doctoral Thesis.

Sanchez-Barroso, G., García-Sanz-Calcedo, J., 2019. Evaluation of HVAC design parameters in high-performance hospital operating theatres. Sustainability 11, 1493.

Santos, R., Aguiar Costa, A., Silvestre, J.D., Pyl, L., 2019. Integration of LCA and LCC analysis within a BIM-based environment. Autom. ConStruct. 103, 127-149.

Seifert, C., Koep, L., Wolf, P., Guenther, E., 2019. Life Cycle Assessment as Decision Support Tool for Environmental Management in Hospitals: A Literature Review. Health Care Management Review, 10.1097/HMR.0000000000000248.

Shahrestani, M., Yao, R., Cook, G.K., 2018. A fuzzy multiple attribute decisionmaking tool for HVAC\&R systems selection with considering the future probabilistic climate changes and electricity decarbonisation plans in the UK. Energy
Build. 15, 398-418.

Spanish Ministry for Ecological Transition, 2019. Emission Factors. Carbon Footprint Registration, Offset and Carbon Dioxide Absorption Projects.

Simonen, K., Rodriguez, B.X., De Wolf, C., 2017. Benchmarking the embodied carbon of buildings. Technology|Architecture + Design 1 (2), 218.

Shuo, C., 2011. System Dynamics Based Models for Selecting HVAC Systems for Office Buildings: a Life Cycle Assessment from Carbon Emissions Perspective. Master Thesis. RMIT University. Australia.

Tang, P. Cass, D., Mukherjee, A., 2013. Investigating the effect of construction management strategies on project greenhouse gas emissions using interactive simulation. J. Clean. Prod. 54, 78-88.

To, W.M., Lai, L.S.L., Lam, K.H., Chung, A.W.L., 2018. Perceived importance of smart and sustainable building features from the users' perspective. Smart Cities 1 (1), $163-175$.

Vares, S., Häkkinen, T., Ketomäki, J., Shemeikka, J., Jung, N., 2019. Impact of renewable energy technologies on the embodied and operational GHG emissions of a nearly zero energy building. Journal of Building Engineering 22, 439-450.

Yeo, Z., Ng, R., Song, B., 2016. Technique for quantification of embodied carbon footprint of construction projects using probabilistic emission factor estimators. J. Clean. Prod. 119, 135-151.

Ylmén, P., Peñaloza, D., Mjörnell, K., 2019. Life cycle assessment of an office building based on site-specific data. Energies 12, 2588.

Zhang, X., Wang, F., 2017. Analysis of embodied carbon in the building life cycle considering the temporal perspectives of emissions: a case study in China. Energy Build. 155, 404-413.

Zhong, S., Hou, X.Y., Clark, M., Zang, Y.L., Wang, L., 2017. Disaster Resilience in Tertiary Hospitals: a Cross-Sectional Survey in Shandong Province, China. International Disaster Health Care. Apple Academic Press, pp. 63-96. 